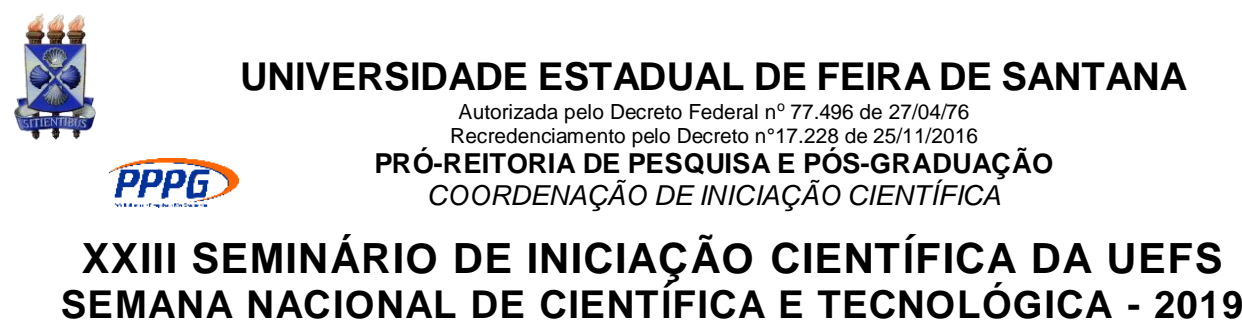

\title{
ALCOOLISMO: percepção dos feirantes do impacto a saúde
}

\author{
Guilherme de Jesus Santos ${ }^{1}$; Tania Maria Costa²; \\ 1. Bolsista PROBIC/UEFS, Graduando em Enfermagem, Universidade Estadual de Feira de Santana, Membro do Núcleo de \\ Pesquisa e Estudo Sobre o Cuidar/Cuidado-NUPEC, e-mail: Guilherme.jsantos@ outlook.com \\ 2. Orientadora, Departamento de Saúde, Universidade Estadual de Feira de Santana, Membro do Núcleo de Pesquisa e Estudo Sobre \\ o Cuidar/Cuidado-NUPEC, e-mail: tmctaniacosta@gmail.com
}

PALAVRAS-CHAVE: alcoolismo; promoção a saúde; feirantes.

\section{INTRODUÇÃO}

O uso de bebidas alcoólicas é um comportamento que varia de acordo com a cultura e costume de cada povo; o consumo pode estar associado a diversos fatores e situações, como festejos comemorativos, eventos culturais, cerimônias religiosas, sucesso em negócios, reuniões de amigos; assim como problemas psicossociais. Contudo, nos dias de hoje o alcoolismo é um dos mais sérios problemas de saúde pública, chamando assim a atenção de autoridades médicas e sanitárias.

Brites e Abreu (2014, p. 94) dizem que há dez anos, o uso nocivo de álcool foi responsável por 3,8\% do índice de mortalidade mundial. Nos estudos de Andrade, Anthony, Silveira (2009), traz que a cada ano, cerca de 2 bilhões de pessoas consomem bebidas alcoólicas, o que corresponde a aproximadamente $40 \%$ (ou 2 em cada 5) da população mundial acima de 15 anos. A nível nacional, o VIGITEL, 2016 (BRASIL, 2017) revela que um dos maiores consumo em excesso de bebidas alcoólicas em uma única ocasião são os moradores da capital baiana, Salvador com $24,9 \%$, e da capital mato-grossense, Cuiabá com $24,1 \%$. Tais indicadores alerta para um grave problema social, tendo em vista que a ingestão sistemática de bebidas alcoólicas pode levar a alteração de ordem física e comportamental no indivíduo, fato que repercute na família e na sociedade.

$\mathrm{O}$ interesse do estudo foi despertado a partir da à observação do elevado consumo de bebidas alcoólicas pelos feirantes enquanto trabalhavam e o fato do consumo de bebidas alcoólicas durante o trabalho ser um agravante para acidente de trabalho (AT), causando prejuízos, como a diminuição na produtividade, perda do lucro e da mercadoria, absenteísmo, e ainda consequências pessoais e familiares.

Buscamos no estudo analisar a percepção dos feirantes que atuam no Centro de Abastecimento de Feira de Santana, sobre o impacto do alcoolismo na sua saúde.

\section{METODOLOGIA}

Trata-se de um estudo qualitativo, descritivo e exploratório, desenvolvido no Centro de Abastecimento de Feira de Santana, BA, cujos sujeitos foram feirantes maiores de 18 anos, classificados no consumo de bebidas alcoólicas em uso nocivo e de provável dependência conforme o instrumento Alcohol Use Disorders Identification Test - AUDIT, num estudo anterior. Dessa feita os dados foram coletados através de entrevista com base num roteiro semiestruturado, e analisados através da análise de conteúdo, conforme Minayo (MINAYO, p. 84, 2011). A proposta foi submetida ao CEP/UEFS, sendo emitido parecer favorável de número 2.642.426.

\section{RESULTADOS E DISCUSSÃO}

Participaram do estudo 13 feirantes de ambos os sexos, sendo cinco do sexo feminino e oito do sexo masculino, com idade na faixa de 21 a 83 anos, desses, sete são solteiros, cinco casados e um viúvo; quanto à cor/etnia, todos se autodeclararam negros (pardos e pretos). Em relação ao grau 
de escolaridade, do total de treze participantes, cinco têm Ensino Fundamental Incompleto, três com Ensino Médio Completo, dois possuem Ensino Fundamental Completo, um com Ensino Médio Incompleto, e dois não alfabetizados. A renda familiar deles variou de menos de um a dois salários mínimos, oito admitiram auferir menos de um salário mínimo e cinco de um a dois salários mínimos ao mês. O tempo de trabalho dos participantes na feira livre foi de três a quarenta anos, em setores como hortifrutigranjeiros, carnes e bijuterias.

Em relação à questão central do estudo salientamos que todos os feirantes entrevistados percebem que o alcoolismo impacta na saúde, causando adoecimento assim, a partir do conteúdo das falas emergiu a categoria adoecimento, e dessa duas subcategorias: adoecimento agudo e crônico; outras duas categorias, a diminuição da produtividade e o comprometimento da autoimagem e da autoestima.

\section{1. Adoecimento}

\subsubsection{Adoecimento agudo}

Qualquer padrão de consumo de álcool pode gerar problemas para o indivíduo, desde o adoecimento agudo, podendo progredir para o crônico; dentre as consequências agudas, uma das mais comuns é a intoxicação alcoólica aguda (IAA) que decorre do elevado consumo de bebidas alcoólicas, relacionadas com a ação direta dessas sobre o Sistema Nervoso Central (SNC) (PIRES, 2013). Ela é caracterizada por efeitos físicos e mentais adversos, com uma variedade de sintomas de "mal-estar", sendo os mais comuns: dor de cabeça, náuseas, problemas de concentração, boca seca, tontura, desconforto gastrintestinal, cansaço, tremores, falta de apetite, sudorese, sonolência, ansiedade, e irritabilidade (VESTER, 2008), algumas dessas manifestações foram evidenciadas nas falas dos entrevistados.

“[...] Por exemplo tontice, dores de cabeça, entendeu? Esses danos assim.” (E03). "Pode, prejudica a saúde, prejudica o cara fica doente por causa da cachaça, fica mal, passa mal, [...]. Nunca fiquei com problema não, mas pode interferir." (E05)

"Interfere no geral[...] Na minha saúde já interferiu, porque já aconteceu de beber e passar dois ou três dias ruim [...].” (E 06)

Os sintomas relacionados pelos feirantes são característicos de IAA, conhecida popularmente como "ressaca", são manifestações dose dependentes, na qual a gravidade está estreitamente relacionada ao consumo propriamente dito (OLIVEIRA; ARNAUTS, 2011).

\subsubsection{Adoecimento crônico}

$\mathrm{Na}$ atualidade está comprovado que o consumo de bebidas alcoólicas gera adoecimento crônico, como lesão no sistema nervoso, no sistema hepático, bem como câncer de tubo digestivo. Lima e outros (2010) conceituam o alcoolismo como consequência do uso abusivo de bebidas alcoólicas, entendendo-o como uma doença crônica, que geralmente é progressiva e fatal; que envolve os fatores genéticos, psicossociais e ambientais influenciando seu desenvolvimento e suas manifestações.

Tal conceito descrito anteriormente, dentre outros salientam o alcoolismo como uma doença crônica, entretanto os feirantes não expressaram o uso abusivo do álcool como uma doença crônica, embora tenham mencionado sobre a dependência. Eles colocam como se o abuso do álcool fosse um hábito de risco, possível de causar adoecimento

“E muito, menino tem alteração de pressão, é, gordura a pessoa engorda mais, problemas cardíacos, e a uma série de problemas que a gente enfrenta aí pela frente. E em mim, até então não." (E 01)

"Pode, em muitos, assim, problemas de pressão alta, problemas nos rim, essas coisas. Quando eu bebo demais, aí minha pressão sobe, ai fico com a pressão alta [...]” (E13)

As falas evidenciam as doenças cardiovasculares, inclusive a Hipertensão Arterial Sistêmica (HAS) essa a mais prevalente do grupo na população brasileira, capaz de gerar complicações cardíacas, renais e Acidentes Vasculares Encefálicos, os quais têm impacto elevado na perda da 
produtividade do trabalho e da renda familiar, estimada em US\$ 4,18 bilhões entre 2006 e 2015 (PLAVNIK et al., 2016).

"Pode, é, ô meu Deus é que eu não sei explicar. Pode interferir na saúde assim, no sangue, né? No fígado, faz mal à saúde. Na minha também, mais ainda não interferiu, que não bebo muito não” (E $\mathbf{0 3}$ )

Em relação ao fígado, salientamos que o órgão é onde se observa as primeiras manifestações deletérias do consumo exagerado de bebidas alcoólicas, que com o passar do tempo, pode se agravar, evoluindo com o processo de morte celular, levando a formação de cicatrizes, situação essa que caracteriza a cirrose hepática. Tendo em vista as diversas funções do fígado, a falência desse órgão significa a morte de todo organismo (ALARCON, 2012).

\subsection{Diminuição da produtividade}

$\mathrm{Na}$ atualidade sabe-se que decorrente da ação no SNC, a ingestão de bebidas alcoólicas é um forte agravante para Acidente de Trabalho (AT), pois sua ação depressiva, causa sonolência, redução da atenção e da concentração, lentidão do pensamento, dos reflexos e certa dificuldade de coordenação motora (NEVEZ; MEIRELLES, 2014), podendo gerar também diminuição na produtividade, no lucro e absenteísmo.

“Interfere no geral, pra mim hoje, sempre atrapalha [...] Na minha saúde já interferiu, [ ...] beber e passar dois ou três dias sem querer fazer nada." (E06)

"Se exagerar, se beber demais, pode causar problemas com a saúde, por exemplo, a gente vai beber vai ficar lerdo, não sabe o que que tá fazendo, tá entendendo? Aí justamente fraqueza no corpo [...]. Dá preguiça, você falta vontade de trabalhar, entendeu? (E 12).

O fato do feirante se afastar do trabalho alguns dias leva a perda da produtividade e a contenção do lucro. Fato que pode interferir diretamente na sustentabilidade e renda familiar de pequenos comerciantes, como os feirantes. Repercutindo também na educação dos filhos, por exemplo, quando ele for o provedor da família, o que é comum em muitos casos. Ocorre também um maior número de conflitos interpessoais, na vivência da IAA, devido a irritabilidade, que pode acarretar a rejeição por parte da clientela e relações "ruidosas" com as pessoas de modo geral, dentre elas, familiares, fregueses e colegas de trabalho.

\subsection{Comprometimento da auto imagem e da auto estima}

O desenvolvimento de uma auto imagem positiva alimenta a certeza de ser capaz de levar uma vida plena e realizada em nossa sociedade, sendo esta imagem estimulante, inquietante ou até decepcionante (BENEDETTI, PETROSKI, GONÇALVES, 2003). Quando o indivíduo desenvolve uma auto estima negativa, ele pode ter consequências como sentimento de inferioridade, carência de afeto, de humilhação e de timidez; esquivando-se ainda de relacionamento interpessoal (SILVA; MARINHO, 2008), como evidenciado na fala do feirante E04.

"Incomoda na saúde, aqui agora eu tô melhor, eu tava magro, agora tô mais cheio no corpo, não tá? [...] fica seco, fica magro e feio, as mulher não quer, 'a quem quer fulano fedendo a cachaça?',

\section{CONSIDERAÇÕES FINAIS}

Salientamos que todos os feirantes entrevistados percebem que o alcoolismo impacta na saúde, causando adoecimento e que todos eles embora categorizados no padrão, em uso nocivo e de uma provável dependência, conforme o AUDIT, não se reconhecem como alcoolistas, ou se reconhecem, mas, negam.

A investigação alcançou o objetivo, os resultados mostraram diversos tipos de impactos, categorizados como adoecimentos, diminuição da produtividade, e o comprometimento da auto imagem e da auto estima.

Considerando especialmente a situação de vulnerabilidade a saúde experimentada pelos feirantes, fato que apontou para a necessidade desse estudo, é de suma a importância o 
desenvolvimento de ações educativas para a conscientização deles sobre o padrão de consumo e os impactos na saúde provocados pelo uso de bebidas alcoólicas.

Salientamos que embora a arrecadação das vendas de bebidas alcoólicas seja expressiva para a economia do país (LARANJEIRA et al., 2014), o estado precisa ter um papel mais efetivo visando a redução do consumo, haja vistas o impacto do consumo abusivo para o individuo, família e sociedade.

\section{REFERÊNCIAS}

ALARCON, S. Drogas Psicoativas: classificação e bulário das principais drogas de abuso. In ALARCON, S. JORGE, M. A. S. Álcool e outras drogas: diálogos sobre um mal-estar contemporâneo. Rio de Janeiro, 2012. Cap. 5, p. 103-129.

ANDRADE, A. G; ANTHONY J. C; SILVEIRA, C. M. Álcool e suas consequências: uma abordagem multiconceitual. Barueri, SP: Minha Editora, 2009.

Crônicas por Inquérito Telefônico - Vigitel Brasil 2017, Brasília, 2018. Disponível em:

http://bvsms.saude.gov.br/bvs/publicacoes/vigitel_brasil_2017_vigilancia_fatores_riscos.pdf. Acesso em: 21 jul 2018.

BENEDETTI, T. B. PETROSKI, E. L. GONÇALVES, L. T. Exercícios físicos, auto-imagem e auto-estima em idosos asilados. Revista Brasileira de Cineantropometria \& Desempenho Humano, v. 5, n. 2, p. $69-$ 74, 2003. ISSN 1980-0037. Disponível em

https://www.researchgate.net/publication/26452377_Exercise_activity_and_self-imageselfesteem_in_nursing_home_residents. Acesso em 29 jul 2019.

BRASIL, Ministério da Saúde. Vigilância de Fatores de Risco e Proteção para Doenças

BRITES, R. M. R.; ABREU, A. M. M. de. Padrão de consumo de bebidas alcoólicas entre os trabalhadores e perfil socioeconômico. Acta Paul Enferm., São Paulo, v. 27, n. 2, p. 93-99. 2014. Disnponivel em: < http://www.scielo.br/pdf/ape/v27n2/0103-2100-ape-27-02-0093.pdf>. Acesso em: 20 mar 2018. LARANJEIRA, R. et al. II Levantamento Nacional de Álcool e Drogas (LENAD) - 2012. São Paulo: Instituto Nacional de Ciência e Tecnologia para Políticas Públicas de Álcool e Outras Drogas (INPAD), UNIFESP, São Paulo, 2014

LIMA, H. P. et al. Significados do feminino no discurso de alcoolistas e a interface com a saúde mental.

Texto Contexto Enferm, Florianópolis, v. 19, n. 3, p. 496-503, 2010. Disponível em:

<http://www.scielo.br/pdf/tce/v19n3/a11v19n3>. Acesso em: 25 fev 2018.

MINAYO, M. C. S. (Org). Pesquisa social: teoria, método e criatividade. 30. ed. Petrópolis - RJ: Vozes, 2011.

NEVES, E. E. D. MEIRELLES, M. A. L. O uso do AUDIT na identificação e estratificação do alcoolismo no contexto da atuação do fisioterapeuta: uma revisão literária. 2014, $44 \mathrm{f}$. Trabalho de Conclusão de Curso (Bacharelado em Fisioterapia), Universidade Federal de Juiz de Fora, Juiz de Fora MG.

PLAVNIK, F. L. Conceituação, epidemiologia e prevenção primária. In: Sociedade Brasileira de Cardiologia, v. 107, n. 3, 2016. ISSN-0066-782x. Cap. 1, p. 1-6.

SILVA, A. I. MARINHO, G. I. Auto-estima e relações afetivas. Universitas Ciências da Saúde, v. 1, n. 2, p. 229-237, 2008. Disponível em

https://www.publicacoesacademicas.uniceub.br/cienciasaude/article/viewFile/507/328. Acesso em 01 ago 2019.

VERSTER, J. C. The alcohol hangover-a puzzling phenomenon. Alcohol \& Alcoholism, v. 43, n. 2, p. 124-126, 2008. DOI https://doi.org/10.1093/alcalc/agm163. Disponivel em https://academic.oup.com/alcalc/article/43/2/124/122754. Acesso em 31 jul 2019. 